Military Technical College Kobry El-Kobbah, Cairo, Egypt

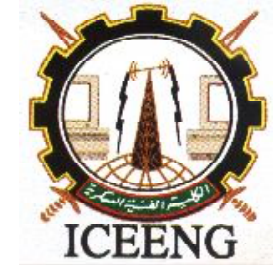

\author{
$10^{\text {th }}$ International Conference \\ on Electrical Engineering \\ ICEENG 2016
}

\title{
Swinging Tension sensor and Control Structure for Gyroscope Fiber Winding Process
}

\author{
By
}

\author{
Ahmed S. Eldessouky ${ }^{1}$ \\ Moshera A. Mohamed ${ }^{2}$
}

\section{Abstract:}

One of the common applications of optical fiber coils is optical gyroscope in which optical fiber has tiny cross-section (order of 100 micro meters). Accordingly, with such characteristics, it is required to maintain tension forces applied to fiber during winding process within very low limits. This paper proposes tension sensor and control structure to achieve high precision of fiber tension during winding process. The advantage of the proposed structure of tension sensing and control mechanism is to relax the control objective. Hence, the proposed mechanism allows the use of high torque motors with slow dynamics and large time constant (required for driving large inertia supply spool), yet achieve high transient performance. In this paper, the proposed tension sensing and control mechanism is introduced, its mathematical model is developed and model accuracy is discussed. A conventional PID controller is introduced in tension control loop to verify the developed model transient performance. The simulation results are presented. The results show the validity of the proposed mechanism and it mathematical model.

\section{Keywords:}

Modeling, Tension control, Optical Gyroscope, Fiber coil winding.

\section{Introduction:}

Optical gyroscopes are instruments that can measure the rotational motion [1, 2]. They do not require any moving parts hence, they have fast reaction time. In addition, they have wide dynamic range, no "g" sensitivity drift and high accuracy and reliability. 
Optical gyroscopes operate based on Sagnac effect principle [3]. The most common used optical gyroscopes are Ring laser gyroscopes (RLGs) and fiber-optic gyroscopes (FOGs) [4]. While RLGs require expensive mirrors and other mechanical components, FOGs represent a cost effective gyroscope.

However, to achieve high accuracy, it is required to develop optical coils with lengthy optical fiber (one or two kilometers) in special pattern windings. FOGs deploy Sagnac effect by injecting two in phase laser beams from the two ends of fiber coil. Hence, the two laser beams will travel inside optical coil in a direction against each other, one of them in the direction of the coil rotational motion and hence its speed increases while the opposite one will travel with slower speed. The emerging beams will have phase shift relatively proportional to the rotational speed of the coil. To increase its accuracy, for detecting very slow angular motion, optical gyros require lengthy fiber winding coil. Length of the fiber winding is proportional to the produced coil weight which negatively affects the FOGs applications. Hence, a tiny optical fiber (order of 100 micro meter diameter) is used for FOGs coils to keep their weight in a reasonable range. With complex winding process and fragile fiber, a possible deformation of the fiber cross section could occur.

Fiber tension control is an essential process in the optical fiber winding system. The winding tension directly influences the quality of winded coil products that makes the winding tension control a key feature in produced optical gyroscopes. Variable tension during winding process could result in deformation of the fiber cross section in different parts, hence refractive index of the fiber will change Resulting in low quality optical gyroscope coils. To avoid fiber deformation during winding process, the fiber tension should be maintained within very low limits defined by fiber characteristics. Therefore, commonly used tension control systems in industrial winding applications cannot satisfy the special characteristic of the optical fiber used for gyroscopes. The speed of the supply spool has significant influence on the fiber tension. The control of such speed to achieve the desired tension is challenging control problem due to slow dynamics of supply spool system (high inertia of the fiber windings and spool).

One of the proposed control techniques for such fiber winding process was to have multiple control loops with single control objective (fiber tension). The main control loop is achieved by controlling the speed of the supply spool while the auxiliary control loop is added by what is called "dancer" mechanism [5]. While the driving system of the supply spool has high inertia and able to rotate the supply spool, the dancer mechanism is driven by low inertia motor. Hence, the dancer mechanism has very fast 
transient response. Accordingly, the tension control performance enhances.

However, the presence of two control loops with one control objective complicate the controller design and reduce the system stability. The challenge is evident when a pressure transducer is used to measure the tension forces. At this case, small variation of the speed between the two driving motors (the supply spool and the product spool motors) would result in abrupt variation on fiber tension. With the presence of large time constant of the supply spool driving motor, the required fast response cannot be achieved [6]. Moreover, there is still inertia for the dancer motor.

This paper introduces a new tension transducer structure that relaxes the control objective and increases the system dynamics even in presence of large inertia driving motors for both source and target spools. The proposed transducer replaces the dancer mechanism, introduced in [5], such that the control objective successfully achieved by one control loop.

The paper is organized as follows: The first section introduces the structure of the proposed optical fiber winding tension control. The second section presents the kinematic model, then section three provides the dynamic model of the driving system, sensor model, tension control system and Simulink model of fiber tension winding system. In the fourth section, the performance of fiber tension control system is verified by comparing mathematical model with real measurement. Finally, conclusion and future work are presented in section five.

\section{THE STRUCTURE OF OPTICAL FIBER WINDING TENSION CONTROL} SYSTEM:

The schematic diagram of tension sensing and control system is shown in Figure (1).The proposed structure composed of three mechanisms, (1) Product spool, (2) Source spool and (3) tension transducer. Both of source and product spools are driven by permanent magnet brushed DC motor (PMBDCM) which is commonly used in low power low voltage applications. The three mechanisms are supported at an aluminum platform. The tension transducer is mounted at the center of the tension mechanism between the two spools. The tension transducer is a rotational potentiometer with its base mounted on the aluminum platform and an aluminum arm is mounted to rotating potentiometer shaft. Two free rotating pulleys are mounted in the far edges of the arm. The shaft of the potentiometer is linked to the platform by calibrated helical spring. 
The optical fiber is wended around two free rotating pulleys at the edges of transducer arm. The helical spring applies forces to the starched fiber between the two pulleys. The applied forces are proportional to the angle of the potentiometer between horizontal line and rotating arm.

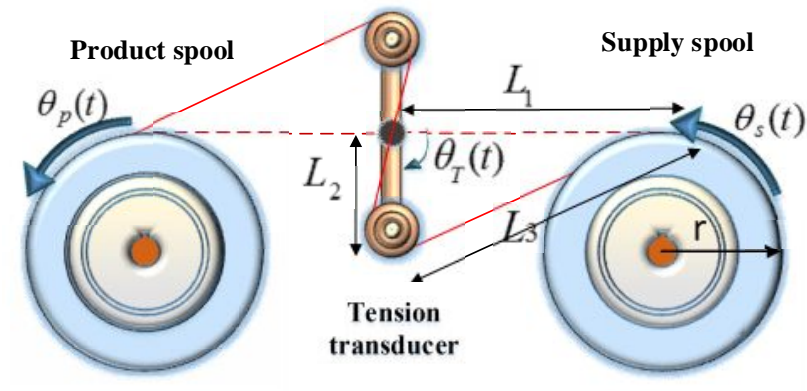

(a)

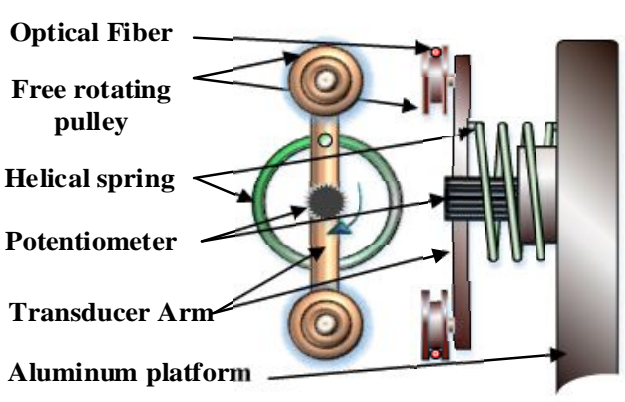

(b)

Figure (1): Schematic diagram of (a) tension sensing and control system and (b) tension transducer Structure

\section{KINEMTIC MODELING:}

The objective of this section is to drive relation between relative angular speed of the supply and product spools and the angular deviation of the transducer arm from its horizontal position $\left(\theta_{\mathrm{T}}(t)\right)$. The transducer angle $\left(\theta_{\mathrm{T}}(t)\right)$ is linearly proportional to the tension produced by the helical spring that links system platform to transducer arm. The cross relation between system geometrical quantities can be driven from Figure (1) (a). At any instance $t, \theta_{\mathrm{p}}(t)$ and $\theta_{s}(t)$ are the product and supply spools angular position respectively, $L_{1}$ is the stretched half-length of optical fiber, $L_{2}$ is the half length of transducer arm, $L_{3}$ is stretched fiber between supply spool and the free rotating pulley at the edge of transducer and $r$ is the radius of the product and supply spools. The transducer deviation angle is proportional to fiber length between the supply spool and the product spool. To avoid complex modeling, the following assumptions are made:

1- The elongation due to tension forces aligned to optical fiber longitudinal axis is neglected. The relative elongation of the fiber due to applied tension forces is given by [7]:

$$
\frac{\Delta \mathrm{L}}{1}=\frac{F}{E_{G} \mathrm{~A}}
$$


where $E_{G}$ is the proportionality constant between the perturbation force per area and the relative deformation (Young modulus). The relative elongation is 0.00075 $\mu \varepsilon$ for $50 \mathrm{~g}$ tension forces which is very small and can be neglected.

2- The curvature of the optical fiber around supply and product spools and free rotating pulleys is neglected. This is valid if $L_{1} \gg r$ and the radius of the free rotating pulleys is much smaller than the half length of the transducer $\operatorname{arm}\left(L_{2}\right)$. A study of this assumption effect on simulation error is introduced at section V.

The tension applied to the optical fiber is proportional to the integration of relative rotational speed $(\Delta \dot{\theta})$ between product and supply spools. The angle of tension transducer $\theta_{\mathrm{T}}$ is proportional to the angular shift between supply spool and product spool $\Delta \theta$. The proportional constant between them is dependent on the dimensions of fiber winding mechanism. The length 1 of tangled optical fiber between the two pulleys (supply and product) is given by:

$\mathrm{l}=\Delta \mathrm{X}+2 \mathrm{~L}_{1}=2\left(\mathrm{~L}_{3}+\mathrm{L}_{2}\right)$

where $\Delta X$ is the linear displacement shift between supply spool and product spool, $\frac{\Delta r}{2}$ is the average thickness of the fiber around the spool. This displacement is proportional to the angular shift between supply motor and product motor $\Delta \theta$ as follow:

$\Delta \mathrm{X}=\Delta \theta \times \mathrm{r}+\frac{\Delta \mathrm{r}}{2}$

And $\Delta \theta$ can be achieved by integrating the speed difference between the product and supply spools as follow:

$\Delta \theta=\int_{0}^{t}\left(\dot{\theta}_{2}-\dot{\theta}_{1}\right) \mathrm{dt}$

From (2) and (3) we get

$2\left(\mathrm{~L}_{3}+\mathrm{L}_{2}-\mathbf{L}_{1}\right)=\Delta \theta \times r+\frac{\Delta \mathrm{r}}{2}$

Hence, $L_{3}$ can be calculated using known dimensions of system $L_{1}, L_{2}, \Delta \boldsymbol{r}$ and $r$

$\mathrm{L}_{3}=\frac{1}{2}\left(\Delta \theta \times \mathrm{r}+\frac{\Delta \mathrm{r}}{2}-\left(\mathrm{L}_{2}-\mathrm{L}_{1}\right)\right)$ 
Finally, the transducer angel $\theta_{\mathrm{T}}$ can be calculated as follow:

$\theta_{\mathrm{T}}=\cos ^{-1} \frac{\mathrm{L}_{2}^{2}-\left(\mathrm{L}_{\mathrm{L}}^{2}+\mathrm{L}_{2}^{2}\right)}{-2 \mathrm{~L}_{1} \mathrm{~L}_{2}}$

\section{WINDING SYSTEM DYNAMIC MODEL:}

The model of optical fiber coil winding was developed for stress and control analysis [4, 8]. In this paper, a modified structure is proposed. The aim of this section is to provide a modified model of proposed winding system for control analysis.

The total damping (friction) of the mechanical system at product driving side $\mathrm{D}_{\mathrm{Tp}}$ is given by:

$\mathrm{D}_{\mathbf{T p}}=\mathrm{D}_{\mathrm{m}}+\mathrm{D}_{\mathrm{pz}}$

where $\mathrm{D}_{\mathrm{m}}, \mathrm{D}_{\mathrm{ps}}$ and $\mathrm{D}_{\mathrm{ss}}$ are damping of motor, product spool and source spool respectively.

Similarly, the total damping (friction) at source side driving $\mathrm{D}_{\mathrm{Ts}}$ is given by:

$\mathrm{D}_{\mathrm{Ts}}=\mathrm{D}_{\mathrm{m}}+\mathrm{D}_{\mathrm{sg}}$

Total moment of inertia of the rotor at product driving side $\mathrm{J}_{\mathrm{TP}}$ is given by:

$\mathrm{I}_{\mathrm{Tp}}=\mathrm{J}_{\mathrm{m}}+\mathrm{J}_{\mathrm{ps}}+\mathrm{J}_{\mathrm{pf}}(\mathrm{t})$

where $J_{m}, J_{p s}, J_{s s}, J_{s f}(t)$ and $J_{p f}(t)$ are moment of inertia of the motor, product spool, source spool, source fiber and the product fiber respectively. The moment of inertia of the winded optical fiber decreases with time as the optical fiber leave source spool and wound around product spool. Similarly, the total inertia at source driving side $\mathrm{I}_{\mathrm{Ts}}$ is given by:

$I_{T s}=I_{m}+I_{s g}+I_{s f}(t)$ 


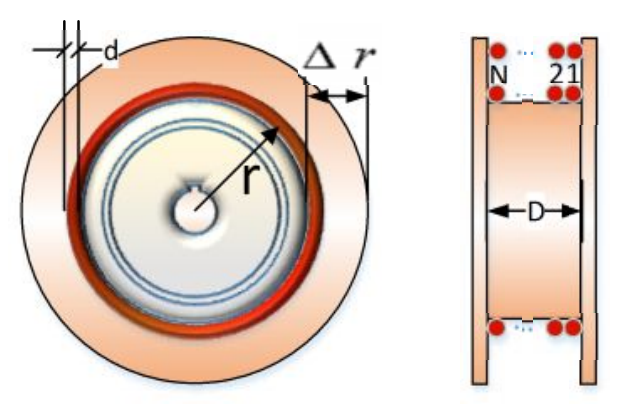

Figure (2): Simplified schematic of optical fiber arrangement around supply and product spool

Figure (2) shows a simplified schematic of optical fiber arrangement around supply and product spool. The number of the layers and rounds is dependent on length of the fiber (L), its diameter (d), width of the spool (D) and its radius (r). If $\rho$ is the fiber density then, the mass per unit length is given by:

$\lambda_{M}=\rho \times \frac{\pi d^{2}}{4}$

The number of rounds per layer is given by:

$\mathrm{N}=\frac{\mathrm{D}}{\mathrm{d}}$

And the number of layers is given by:

$N_{L} \cong \frac{L}{2 \pi r N}$

Hence, the thickness of the fiber around the spool per unit length is given by:

$\sigma=\frac{\mathrm{N}_{\mathrm{L}} \times \mathrm{d}}{\mathrm{L}} \cong \frac{1}{2 \pi \mathrm{N} N} \times \mathrm{d}$

Accordingly, the total thickness of the fiber around the spool is given by:

$$
\Delta \mathrm{r}=\sigma \times \mathrm{L}
$$

And the instantaneous length of the fiber around the spool is given by:

$\ell(\mathrm{t}) \cong(\mathrm{r}+\Delta \mathrm{r} / 2) \int_{0}^{\mathrm{t}} \omega(\mathrm{t}) \cdot \mathrm{dt}$

Hence, the instantaneous length of the fiber around the source spool is given by:

$\ell_{s}(\mathrm{t}) \cong \mathrm{L}-(\mathrm{r}+\Delta \mathrm{r} / 2) \int_{0}^{\mathrm{t}} \omega_{s}(\mathrm{t}) \cdot \mathrm{dt}$ 
with initial length $\ell_{s}(0)=\mathrm{L}$

And the instantaneous length of the fiber around the product spool is given by:

$$
\ell_{p}(t) \cong(r+\Delta r / 2) \int_{0}^{t} \omega_{p}(t) \cdot d t
$$

with initial length $\ell_{\mathrm{p}}(0)=0$

Based on equations (12), (15) and (18) the instantaneous moment of inertia for the fiber winding around the Source spool is given by:

$J_{g f}(t)=\lambda_{M} \times\left(\ell_{s}(t)\right) \times\left(r+\left[\sigma \times\left(\ell_{s}(t)\right)\right] / 2\right)^{2}$

Similarly, the instantaneous moment of inertia for the fiber winding around the product spool is given by:

$\mathrm{J}_{\mathrm{pf}}(\mathrm{t})=\lambda_{\mathrm{M}} \times\left(\ell_{\mathrm{p}}(\mathrm{t})\right) \times\left(\mathrm{r}+\sigma \times\left(\ell_{\mathrm{p}}(\mathrm{t}) / 2\right)^{2}\right.$

The optical fiber is extended from the source spool to the product spool through free rotating pulleys supported at far ends of transducer arm. As the tension increases, the potentiometer rotates squeezing the spring. When the tension decreases, the potentiometer rotates stretching the spring and relaxing fiber tension. The angle of the potentiometer is proportional to the fiber tension. According to the above analysis, the establishment of the optical fiber tension model is done. The transfer function of $\mathrm{dc}$ motor with product spool $[6,9]$, is given by:

$\frac{\theta_{p}(s)}{V_{\mathrm{gp}}}=\frac{K_{m}}{\left[\left(R_{\mathrm{g}}+\mathrm{I}_{\mathrm{g}} \mathrm{s}\right)\left(\mathrm{UTT}_{\mathrm{p}}\right) \mathrm{s}+\left(\mathrm{D}_{\mathrm{Tp}}\right)\right]+\mathrm{K}_{\mathrm{m}} \mathrm{K}_{\mathrm{g}}}$

Where $V_{\mathrm{ap}}$ is the product armature voltage and $\dot{\theta}_{\mathrm{p}}(\mathrm{S})$ is the angular velocity of the product shaft in $\mathrm{rad} / \mathrm{s} . \mathrm{K}_{\mathrm{b}}$ is the back electromotive force constant, $\mathrm{K}_{\mathrm{m}}$ is the motor torque constant, $R_{a}$ is the armature resistance, and $L_{a}$ is the armature inductance.

The mathematical model of product dc motor with spool is shown in Figure (3) (a). 


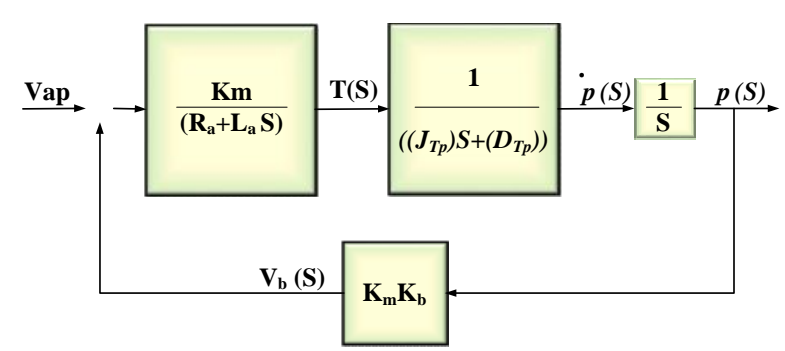

(a)

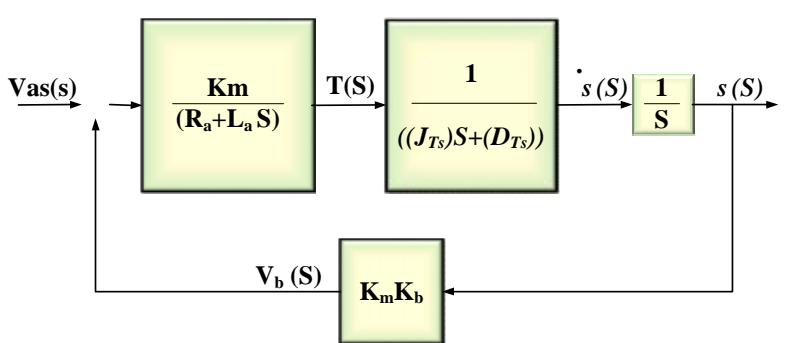

(b)

Figure (3): Mathematical model of (a) product dc motor with spool and (b) supply dc motor with spool

The input to the product motor is $V_{a p}$. The measured variables are $\dot{\theta}_{p}(s)$ and the shaft angle $\theta_{\mathrm{g}}(S)$ in rad [10]. The transfer function of dc motor with source spool, is given by:

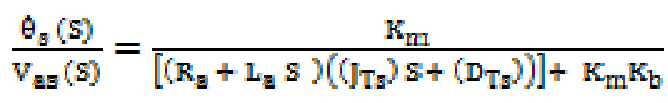

where $V_{a s}(S)$ is the supply armature voltage and $\dot{\theta}_{s}(S)$ is the angular velocity of the supply shaft in $\mathrm{rad} / \mathrm{s}$. The mathematical model of supply dc motor with spool is shown in Figure (3) (b).

The input to the supply motor is $\mathrm{V}_{\mathrm{as}}(\mathrm{S})$. The measured variables are $\dot{\theta}_{\mathrm{s}}(\mathrm{S})$ and the shaft angle $\theta_{s}(S)$ in rad. Figure (4) shows the physical structure of the tension transducer and its schematic presentation. The tension transducer consists of damper and spring [8] that produces tension forces proportional to angular rotation [11].
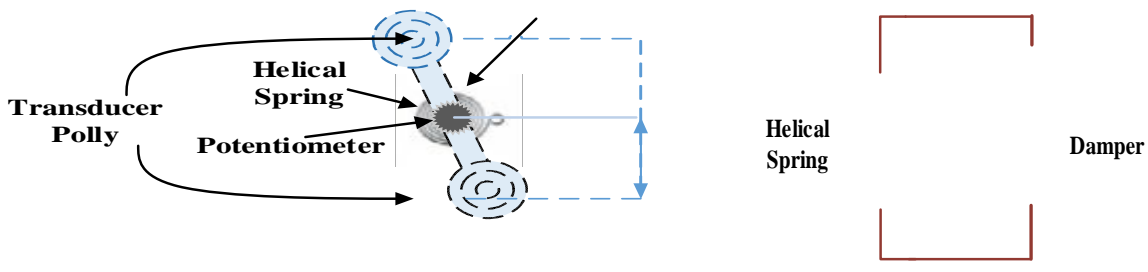

Figure (4): Tension transducer (a) physical structure and (b) its schematic presentation The transfer function of tension transducer is given by:

$f(S)=-\frac{I_{\operatorname{sen}} s^{2}+D_{s e n} S+K_{s e n}}{2 L_{z}} \theta_{T}(S)+f_{0}$

where $f(S)$ is the tension forces applied to the fiber, $I_{\text {sen }}$ is the moment of inertia of the tension transducer, $\mathrm{D}_{\mathrm{sen}}$ is the damping (friction) of the tension transducer, $\mathrm{K}_{\mathrm{sen}}$ is a 
constant factor of transducer spring and $f_{0}$ is the initial tension experienced by the fiber due to initial torque applied by the initially twisted spring. The negative sign at the first term of equation (24) indicate that the measured angle is against the torque direction and hence the fiber tension direction (the tension decreases as the measured angle increases).

The winder testing machine simulation model is shown in Figure (5). The control input to the system is voltage source $V_{a s}(S)$. The monitored output is $f(S)$ to be regulated using a Proportional-Integral-Derivative controller (PID controller).

The rotor and the pulley are assumed to be rigid. The armature inductance of supply and product motor are neglected. The friction of tension transducer is twice the friction of the motor.

Consider the following simulation values for the physical parameters shown in Table (1).

Table (1): Parameter values for the Winder Testing Machine Simulink Model

\begin{tabular}{|c|c|c|c|c|c|}
\hline Symbol & Value & Unit & Symbol & Value & Unit \\
\hline $\mathrm{D}_{\mathrm{m}}, \mathrm{D}_{\mathrm{pg}}, \mathrm{D}_{\mathrm{gsg}}$ & 0.01 & N.m/rad.s & $K_{p}$ & 400 & \\
\hline $\mathrm{D}_{\operatorname{sen}}$ & 0.015 & N.m/rad.s & $K_{i}$ & 3000 & \\
\hline$I_{m n}, J_{g g} J_{s E}$ & 0.43 & g.m2 & $K_{d}$ & 5 & \\
\hline$I_{\operatorname{sen}}$ & 0.00001 & g.m2 & $\mathrm{d}$ & 100 & $\mu \mathrm{m}$ \\
\hline $\mathrm{K}_{\mathrm{m}}$ & 0.01 & N.m/A & $P[12]$ & 2200 & $\mathrm{Kg} / \mathrm{m} 3$ \\
\hline $\mathrm{K}_{\mathrm{b}}$ & 0.01 & $\mathrm{~V} /(\mathrm{rad} / \mathrm{s})$ & $\mathrm{D}$ & 10 & $\mathrm{~mm}$ \\
\hline$K_{\operatorname{sen}}$ & 0.01 & $\mathrm{~N} / \mathrm{rad}$ & $\mathrm{L}$ & 2000 & $\mathrm{~m}$ \\
\hline$R_{a}$ & 10 & Ohm( ) & $\mathrm{r}$ & 3 & $\mathrm{~cm}$ \\
\hline
\end{tabular}




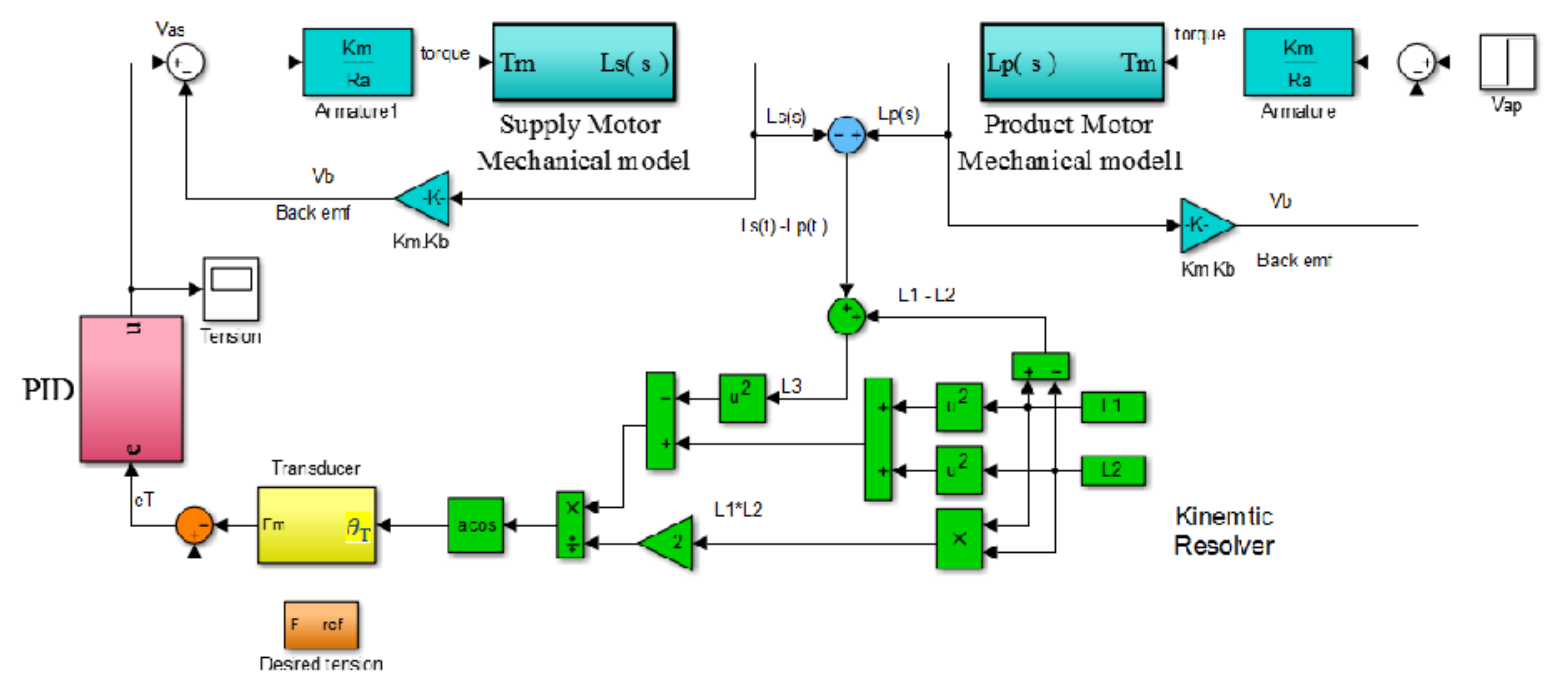

Figure (5): Simulink model of the fiber tension winding system

\section{TENSION SYSTEM OPEN LOOP SIMULATION:}

The simulation of tension control model is conducted using Simulink whereas the physical design of the system was conducted using testing machine. The relation between $f(S)$ and the angle $\theta_{T}$ will be illustrated in this section. In addition, the effect of transducer dimension change to model accuracy will be examined.

\section{A.Simulation Result without motors:}

The experimental and Simulation results of the sensor angular deviation, for tension transducer arm of $60 \mathrm{~mm}$ length, are shown in Figure (6) (a). It is clear that when the tangled optical fiber length $\left(2\left(L_{2}+L_{3}\right)\right)$ increases, angle $\theta_{T}$ increases and the error between the actual and simulated $\theta_{3}$ increases as well. The error curve is shown in Figure (6) (b).
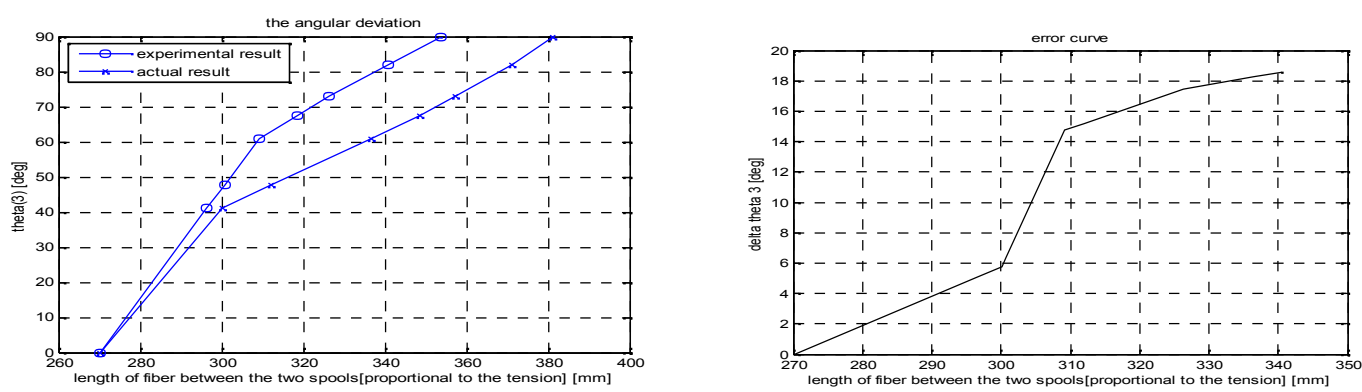

Figure (6): MATLAB Simulation result for (a) the experimental and actual of angular deviation at arm length of $60 \mathrm{~mm}(\boldsymbol{b})$ error due to approximations. 
To show the effect of changing the length of tension transducer arm, a second simulation is conducted with the arm's length of $90 \mathrm{~mm}$. The experimental and actual results shown in Figure (7) indicate that the error decreases when using larger transducer arm.
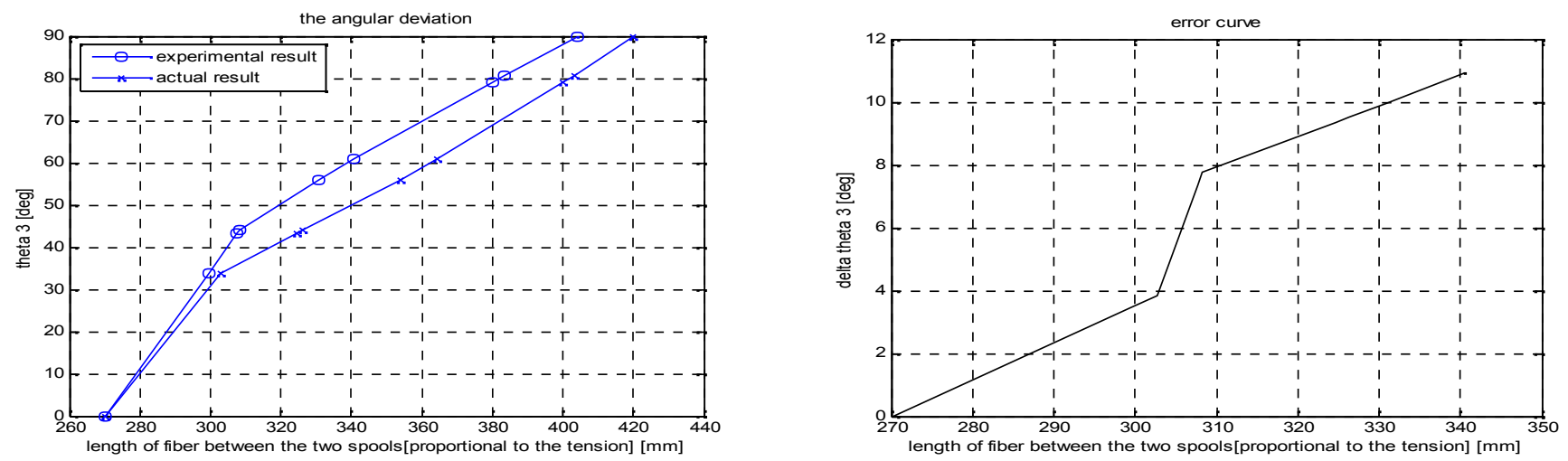

Figure (7): MATLAB Simulation result for (a) the experimental and actual of angular deviation at arm length of $90 \mathrm{~mm}(\boldsymbol{b})$ error due to approximations.

The comparison between different arm lengths in MATLAB simulation result is shown in Figure (8). It can be seen that the error between simulation and measured angular deviations decreases with the increase of the tension transducer arm's length where the arc length of the fiber that is wrapped on tension transducer pulley decreases.

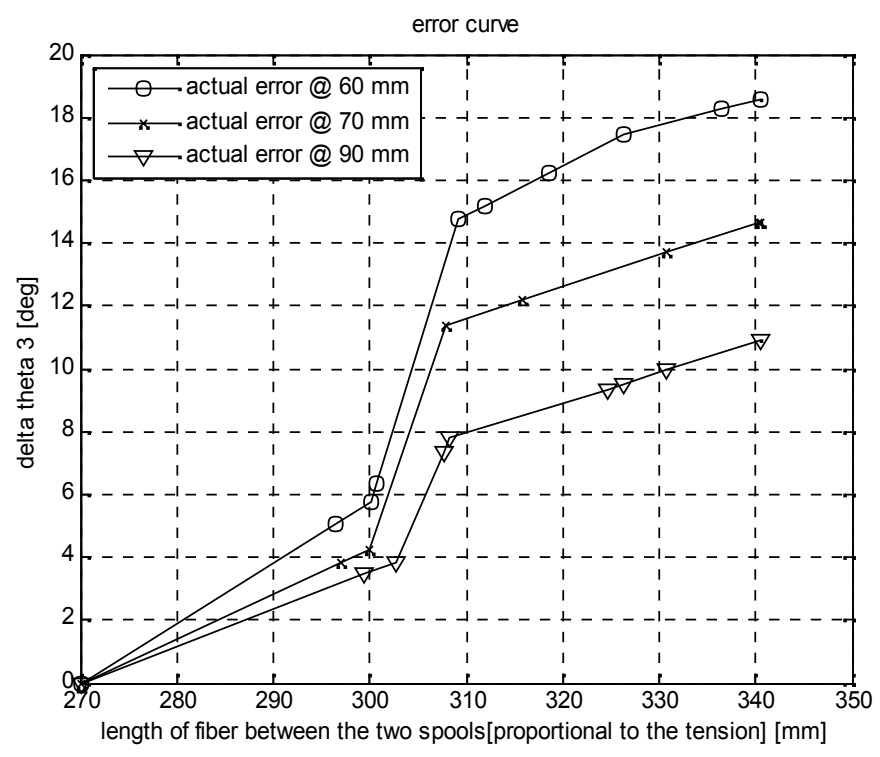

Figure (8): MATLAB Simulation result for the comparison between the three arm lengths 


\section{SIMULATION RESULT OF TENSION SYSTEM WITH PID CONTROLLER:}

The simulation of tension control model applying PID controller is conducted for different winding stages. The result of the simulation is shown in Figure (9). The tension is regulated using the source spool drive. At early stage, shown in Figure (9) (a), the moment of inertia for source drive with mechanism and fiber coil is large. This is because almost total fiber is wounded around source spool. Figure (9) (b) shows the simulation result after $40000 \mathrm{sec}$ at which almost the fiber is split between the two spools. It can be noted that the transient performance improved. After $80000 \mathrm{sec}$, most of the fiber left the source spool and wounded around the product spool. The source spool mechanism has the minimum inertia and the transient performance is much improved as shown in Figure (9) (c).

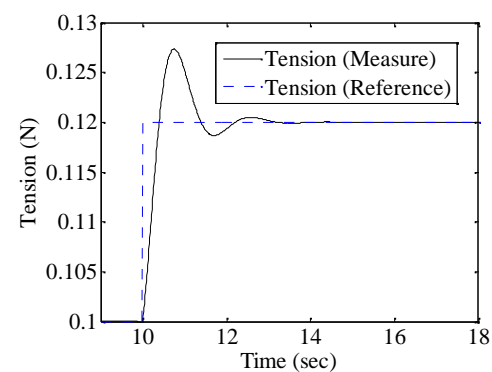

(a)

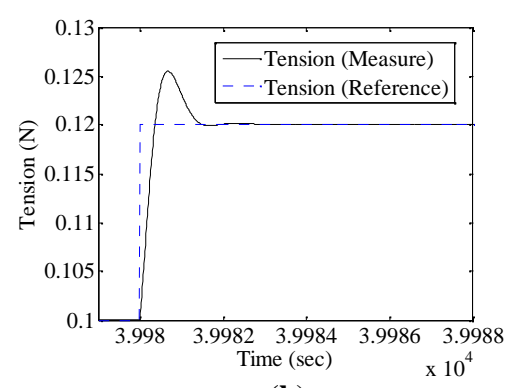

(b)

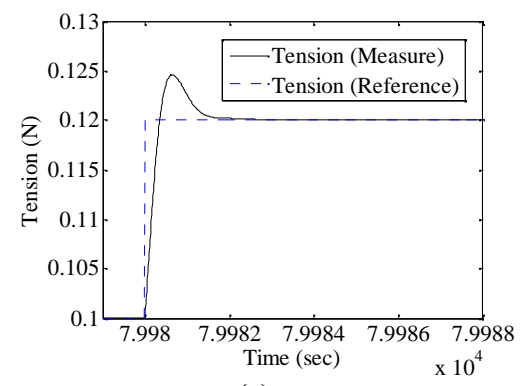

(c)

Figure (9): MATLAB Simulation of the fiber tension winding system with PID controller for different winding stages (a) time from 0 to $10 \mathrm{sec}$, (b) time from 39980 to $39988 \mathrm{sec}$ and (c) time from 79980 to $79988 \mathrm{sec}$,

\section{Conclusions and future work:}

This paper presents modeling, simulation, and analysis of the optical fiber winding tension control system applying a proposed tension transducer and control structure. The models of the tension transducer and control structure have been conducted. A comparison between the simulation results of the transducer measurements and the actual measurements has been presented. The results show that the model error is acceptable within required tension dynamic rage. Furthermore, the more the length of the sensor arm increases, and the sensor pulley diameter decreased, the more the accuracy increases.

In addition, the simulation of the PID controller is presented. The simulations results show that using a simple controller design provides high transient and steady state 
performance. That is because the proposed structure composes all control loops into one control loop and relaxed the relation between the control action and the control objective (motor speed and fiber tension). The simulations were carried out for different winding stages. The effect of inertia changing with time for both source and product mechanism was examined. The effect of inertia time varying to transient performance is evident.

As for future work, Adaptive Fuzzy-PID Controller will be implemented. The nonlinearity of the fuzzy controller would compensate for the nonlinearity relation that maps the measured angle of the tension transducer and the actual fiber tension in addition to other nonlinearity presented in the system. Moreover, the adaptation mechanism would adapt the controller to compensate for the variation of the system parameters during the winding process (inertia of source, product spools, and their diameter change during the winding process).

\section{References:}

[1] D. Z. Anderson, "Optical Gyroscopes," Scientific American, vol. 254, no. 4, pp. 94-99, April 1986.

[2] E. J. Post, "Sagnac effect," Rev. Mod. Phys, vol. 39, pp. 475-93,, 1967.

[3] J. Nayak and P. D. Pinnoji, "Advanced optical gyroscopes," in Workshop on Recent Advances in Photonics (WRAP), 2013.

[4] A. Sharon, S. L. Sharon and S. Lin, "Development of an automated fiber optic winding machine for gyroscope production," Robotics and Computer-Integrated Manufacturing, vol. 17, p. 223-231, June 2001.

[5] B. Ma and S. Dong, "The Modeling of Tension Control System in Optical Fiber Automatic Windin," in International Conference on Mechanic Automation and Control Engineering (MACE), Wuhan, China, June 2010.

[6] A. A. Mahfouz, M. M. K. and F. A. Salem, "Modeling, Simulation and Dynamics Analysis Issues of Electric Motor, for Mechatronics Applications, Using Different Approaches and Verification by MATLAB/Simulink," I.J. Intelligent Systems and Applications, no. April , pp. 39-57, 2013.

[7] P. Antunes, F. Domingues, M. Granada and P. André, "Selected Topics on Optical Fiber Technology," Intech, 2012, pp. 538-550.

[8] G. Y. Ming JIA, "Research of Optical Fiber Coil Winding Model Based on Largedeformation Theory of Elasticity and Its Application," Chinese Journal of Aeronautics, vol. 24, pp. 640-647, 2011. 
[9] A. Zaki and S. Ibrahim, "Modeling and analysis of PM brushed DC motor using FEM," in Power Electronics and Applications, 2005 European Conference on, Sept. 2005.

[10] S. Stramigioli and R. Babuska, "Matlab and Simulink for Modeling and Control," Delft University of Technology, Netherlands, Nov 1999.

[11] N. S. Nise, Control Systems Engineering, Sixth ed., WILEY International, 2011.

[12] M. C. J. Large, L. Poladian, G. W. Barton and M. A. v. Eijkelenborg, "Microstructured Polymer Optical Fibres", Springer, 2008.

\section{Nomenclatures:}

$\theta_{\mathrm{p}}(\mathrm{t}) \quad \ldots$ Product angular position

$\theta_{s}(t) \quad \ldots$ Supply angular position

$\mathrm{L}_{1}$

... The stretched half length of the optical fiber

$\mathrm{L}_{2}$

... The half-length of the transducer arm

$\mathrm{L}_{3} \quad \ldots \quad$ The stretched fiber length between supply spool and the free rotating pulley at the edge of transducer.

r $\quad \ldots$ The radius of the product and supply spools

$\frac{\Delta \mathrm{L}}{1} \quad \ldots \quad$ The relative elongation of the fiber due to applied tension forces

$E_{G} \quad \ldots \quad$ The proportionality constant between the perturbation force per area and the relative deformation

$\Delta \theta$

... The angular shift between supply motor and product motor

1 ... The length of tangled optical fiber between the two pulleys (supply and product)

$\Delta \mathrm{X} \quad \ldots$ The linear displacement shift between supply spool and product spool 
$\frac{\Delta \mathrm{r}}{2} \quad \ldots \quad$ The average thickness of the fiber around the spool

L ... Length of the fiber

d ... Fiber diameter

D ... Width of the spool

$\rho \quad \ldots$ The fiber density

$\lambda_{M} \quad \ldots$ The mass per unit length

$\mathrm{N}$... The number of fiber rounds per layer

$\mathrm{N}_{L} \quad \ldots$ The number of fiber layers

$\sigma \quad \ldots$ The thickness of the fiber around the spool per unit length

$\Delta r \quad \ldots \quad$ The total thickness of the fiber around the spool

$\ell(t) \quad \ldots$ The instantaneous length of the fiber around the spool

$\ell_{s}(t) \ldots$ The instantaneous length of the fiber around the source spool

$\ell_{P}(t) \quad \ldots$ The instantaneous length of the fiber around the product spool

$D_{T S} \quad \ldots$ The total damping (friction) of the mechanical system at supply driving

$\mathrm{D}_{\mathrm{Tp}} \quad \cdots$ The total damping (friction) of the mechanical system at product driving

$\begin{array}{llll}D_{m} & \ldots & \text { Motor damping }\end{array}$

$D_{p s} \quad \cdots \quad$ The damping of product spool

$D_{s s} \quad \ldots$ The damping of source spool

$I_{T s} \quad \ldots$ Total moment of inertia at supply driving side

$\mathrm{I}_{\mathrm{Tp}} \quad \ldots$ Total moment of inertia at product driving side

$J_{m} \quad \ldots$ A moment of inertia of the motor

$I_{p s} \quad \ldots$ A moment of inertia of product spool

$J_{s s} \quad \ldots \quad$ A moment of inertia of the source spool

$\mathrm{J}_{\mathrm{sf}}(\mathrm{t}) \quad \ldots$ The instantaneous moment of inertia of the source fiber

$\mathbf{J}_{\mathrm{pf}}(\mathrm{t}) \ldots$ The instantaneous moment of inertia of the product fiber

$f(S)$

... Tension force of the optical fiber

$\mathrm{J}_{\operatorname{sen}}$

... The moment of inertia of the tension transducer 
$\mathbf{D}_{\text {sen }}$

... The damping (friction) of the tension transducer

$\mathrm{K}_{\text {sen }}$

... A constant factor of transducer spring

$\mathrm{V}_{\mathrm{b}}(\mathrm{t}) \quad \ldots$ The back electromotive force (back emf)

$\mathrm{K}_{\mathrm{b}} \quad \ldots$ The back electromotive force constant

$\mathrm{T}_{\mathrm{m}}$ (S) ... The motor torque

$\mathrm{K}_{\mathrm{m}} \quad \ldots \quad$ A motor constant of proportionality

$\mathrm{R}_{\mathrm{a}} \ldots$ The armature resistance

$\mathrm{L}_{\mathrm{a}} \quad \ldots$ The armature inductance

$\mathrm{V}_{\mathrm{ap}}(\mathrm{S}) \quad \ldots$ The product armature voltage

$V_{\mathrm{as}}(\mathrm{S}) \quad \ldots$ The supply armature voltage

$\dot{\theta}_{s}$ (S) ... The angular velocity of the product shaft in $\mathrm{rad} / \mathrm{s}$

$\dot{\theta}_{\mathrm{p}}(\mathrm{S}) \ldots$ The angular velocity of the product shaft

$K_{p} \quad \ldots$ Proportional gain

$K_{i} \quad \ldots \quad$ Integral gain

$K_{d} \quad \ldots$ Derivative gain 